\title{
SAFETY AT THE NURSE'S WORK WITH CYTOSTATICS - ANALYSIS AND ASSESSMENT OF THE PROBLEM
}

\author{
T. Paskaleva*, Zh. Tencheva, K. Kostov
}

Department "Healthcare", Branch Haskovo of the Trakia University, Stara Zagora, Bulgaria

\begin{abstract}
To provide a better quality of the healthcare, it is of significant importance for the nurses to implement their activities in safe and healthy labour conditions. It is a wellknown fact that their work is connected with the direct influence of a wide range of factors that are hazardous for the health ( biological, physical, chemical, psycho-social and others ), which exert considerable influence on the dynamics of the professional disorders.

The research that was conducted throws light over the safety conditions of the hospital environment and it also assesses the level of the knowledge and skills of the nurses for keeping the safety measures while working with cytostatics.

This group of medications finds a wide application in the curing of a number of malignant diseases, but the different active substances render toxic and infavourable effects on the people working with them. This requires an adequate risk assessment, organisation of a safe environment and application of personal safety measures by the medical personnel.
\end{abstract}

Key words: protective means, safety, nurses, cytostatics

\section{INTRODUCTION}

During the past years health protection and safe working conditions have a great importance in the hospital and pre-hospital care. A number of research define healthcare as a highly risky sector, and the zones and activities that have a potential risk are more than plenty.

To be provided quality of the healthcare, it is of great significance that the nurses do their job in safe and healthy conditions. It is a fact that their activity is connected with the direct impact of a wide range of hazardous for the health factors (biological, physical, chemical, psychosocial and others), which influence to a great extent the dynamics of the professional diseases.

For the patients with malignant diseases the cytostatic medicines are a hope, necessity and also a part of their therapeutic plan.

*Correspondence to: Tanya Paskaleva, Department "Healthcare" Branch Haskovo of the Trakia University, Bulgaria, paskaleva666@abv.bg
The number of patients who undergo a treatment with cytostatics is increasing and this leads to an increase of the number of people who operate and manipulate with these medicinal means. The cytostatic therapy is becoming a routine activity. There is also a constant increase of the medicines from this group. The different active substances, however, render unfavorable impact on the people working with them. This requires adequate risk assessment, organization of a safe environment and application of measurements for personal safety by the medical personnel.

The people working in the healthcare may have a contact with cytostatic medicines at different levels:

- At preparing the infusion mixtures;

- At transportation;

- At application of cytostatic medicines in the ward;

- At patients' attending;

- At cleaning activities [1]. 
The clinical examinations and the follow-up of patients who take anti-cancer medicines in the clinical practice are mainly directed at the medicine's effects, connected to the planned treatment, and the data for the effects at the medical personnel are sparse.

There have been reported unwanted systematic reactions of the cytostatic medicines at the medical personnel vomiting and a loss of the eyelashes of the nurses (according to Jung (1990), cytostatics in the urine of pharmacists and nurses working with cytostatic solutions (Sessink et al. 1992, 1994), spontaneous abortions with nurses and menstrual dysfunction, and also infertility. Other alarming facts are also allergies, asthma, headache, dizziness, change in the blood indices and others, and the local unwanted effects are connected to irritation of the mucous membrane, pigmentation of the skin and dermatitis, damage of the cornea when a cytostatic goes into the eyes and others [2].

Many of the cytostatic medicines that are used nowadays have mutageneous, cancer and/or teratogeneous effects. In case of appearing a malignant disease with medical personnel, working with cytostatics, they are not viewed as an etiological factor. In spite of that, observations show that such a connection cannot be excluded.

In the oncology pharmacy are described and applied two systems for preparation and application of cytostatics - centralized and decentralized. Each of them has their own pros and cons. In our country (excluding "Tokuda" and UMHAT "St. George" Plovdiv hospitals) the preparation of the cytostatics for application is decentralized and is made in special sectors in the chemotherapy wards. [3].

The sectors provide working conditions in aseptic environment. They are supplied with a camera, which allows for sterile preparation of the medicine, and it is also connected to a special ventilation system that provides stream of sterile air and does not permit contaminated with cytostatics air to go into the outer environment. They work with the so called closed system - a device for transferring of the medicine that mechanically prevents detergents from the outer environment to enter the system and it also stops flowing of hazardous concentrations of the medicine or its steams out of the system. Using such systems makes the application of chemotherapeutic medicines safer. Through the usage of closed systems is avoided contamination of the environment while transporting ready for application medicines from the specialized sector to the ward.

In the European practice it is widely applied the centralized dissolving of cytostatics in the pharmacies. The dissolving is made in special small rooms while keeping strict rules, which decreases the contamination both in the premises, and also on the people who work with there. The number of the people potentially imposed on the impact of cytostatics must be as minimal as possible. The centralized dissolving of the cytostatics in the pharmacies is the most reliable, at the moment, method worldwide for safe work with them. Other advantages of this highly technological system, besides the high degree of safety for the personnel are: economical effect, smaller expenses and maximum usage of the vial, the pollution is decreased, and also there is increased security for the patients. The considerable expense for the initial investment in most of the cases (having in mind the real financial situation in the healthcare sector) is the reason to have difficulties in the application of this innovative practice in our country.

\section{AIM}

To be researched the level of knowledge and skills of the nurses in connection to keeping the safety measurements in the work with cytostatics.

\section{MATERIALS AND METHODS}

The research is conducted in the period 20 - 25 March 2015. The applied methods are: direct anonymous questionnaire, analyses of the literary sources, documentary method. There has been conducted a questionnaire research with 48 nurses, working in SBALO Haskovo, Complex oncology center Stara Zagora and Complex oncology center Plovdiv. The questionnaire has 10 questions, developed specially for this aim. The data have been processed through statistic and graphic analysis.

\section{RESULTS AND DISCUSSION}

We followed the age division of the researched respondents (Table 1)

The necessary measurements for healthy and safe working conditions include provision of the necessary organization and means for preventing professional risks, as well as giving information and trainings. 
Table 1.

\begin{tabular}{|l|c|c|c|c|}
\hline Age of the respondents & $25-35$ & $36-45$ & $46-55$ & $56+$ \\
\hline Number of people (n) & 1 & 19 & 16 & 1 \\
\hline
\end{tabular}

In the training of the students in the specialty "Nurse" in Branch Haskovo of the Trakia University in the modules „Nurse care for patients with oncology diseases", and also in the optional discipline "Safety in the nursing practice“ are studied the main theoretical and practical knowledge on that topic, but these are fundamental knowledge, which must be overbuilt regarding the specifics and the novelties in the sphere through specialized courses and other forms of postgraduate qualifications.

When they were asked: „Have you ever had a preliminary training to work with cytostatics?" (Figure 1) the highest is the percentage of the respondents that have been trained to work with cytostatics at their workplace $81 \%(n=39)$.

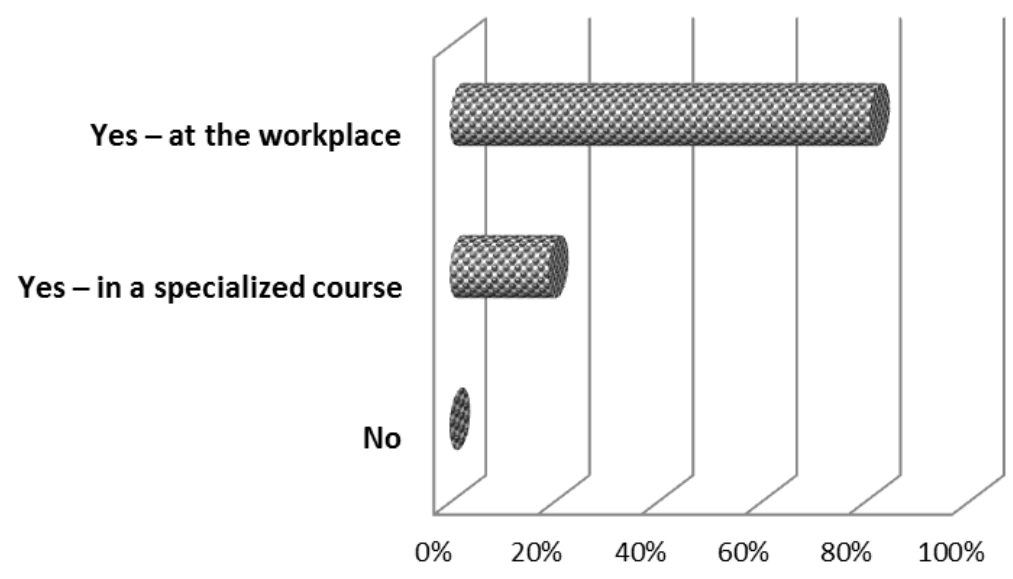

Figure 1. Have you ever had a preliminary training with cytostatics?

Not all measurements for health promotion on the workplace turn out to be effective. The preventive measurements that are connected only with conveying information in the form of explanations and instructions are not useful enough and do not achieve the desired results. There are serious arguments that are evidential that the effectively proven forms for this aim are specialized training courses in which have participated only $19 \%$ $(n=9)$ of the questioned nurses.

The biggest is the group of the respondents who have explicitly stated that they would like to participate in educational seminars and courses (71\%) (Figure 2).

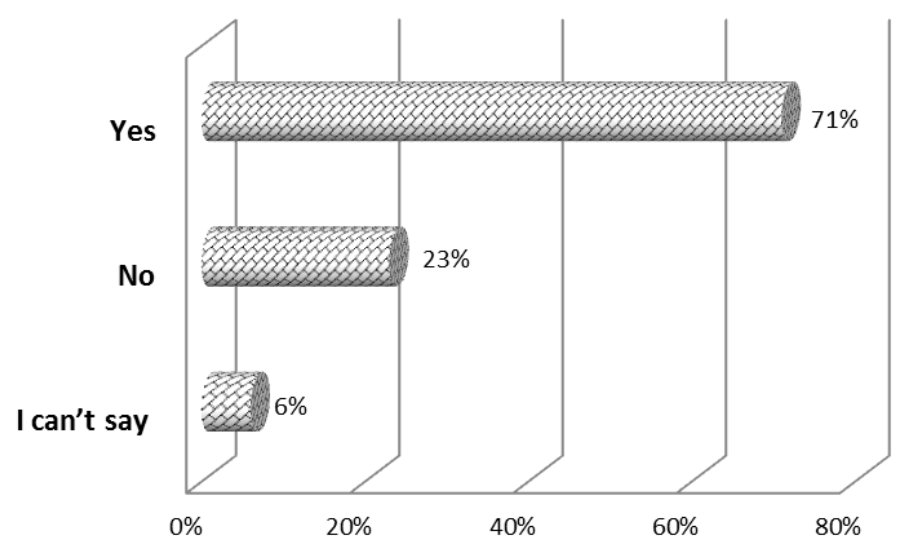

Figure 2. Would you like to participate in educational seminars and courses?

To the question: „Do you know the toxic and unfavorable effects of the cytostatics on the health of the people working with them?"،, $73 \%$ of the questioned have answered positively and $27 \%$, unfortunately, 
demonstrate deficit of knowledge on that topic.

The obligations for the application of the measurements for health and safe working conditions are not the sole responsibility of the employer. In Article 13 of the Directive 89/391/EIO is declared that: „Every employee is obliged, as much as possible, to take care of his/her safety and health, as well as for the safety and health of the other people, affected by his/her action or inaction at work in compliance with his/her training and the employer's instructions. " [4]

Full protection of the people working with cytostatics can be achieved with the simultaneous usage of personal protection means, proper equipment and complying with the organizational and production procedures. The operating at present directives, decrees and tendencies define as obligatory the usage of protective means from the personnel.
The personal protective means must be in compliance with the standards of the European Union - they are one-use only, waterproof, stable under the impact of the cytostatic agents and include:

- Protective overalls - they must be long enough (to cover the thighs) and must be closed up to the neck. They have long sleeves with tightly fitting wristbands. To keep the sterility of the medicine, they must be sterile and to dissociate as few as possible particles;

- Cytostatic gloves with wristbands from latex, neoprene, polyurethane, nitril, PVC;

- Respiratory mask;

- Hat;

- Protective glasses - to provide protection of the eye and to be able to be put onto a dioptrically ones;

- Protective shoes - they must repulse liquids, to cover the foot as much as possible.

Table 2. Personal protective means for working with cytostatics.

\begin{tabular}{|l|l|l|l|}
\hline Personal protective means & Always & Not always & Never \\
\hline Cytostatic gloves & $71 \%(34)$ & $29 \%(14)$ & $0 \%(0)$ \\
\hline Protective overall & $52 \%(25)$ & $31 \%(15)$ & $17 \%(8)$ \\
\hline Respiratory mask & $52 \%(25)$ & $31 \%(15)$ & $17 \%(8)$ \\
\hline Hat & $20 \%(17)$ & $25 \%(12)$ & $40 \%(19)$ \\
\hline Protective glasses & $10 \%(5)$ & $27 \%(13)$ & $63 \%(30)$ \\
\hline Protective shoes & $29 \%(14)$ & $29 \%(14)$ & $42 \%(20)$ \\
\hline
\end{tabular}

The results show a serious negligence regarding the work with personal protective means. Cytostatic gloves, protective overalls and a respiratory mask are among the most widely-used preventive means according to more than $50 \%$ of the researched. A hat, gloves and protective shoes are used more rarely.

The measurements connected with cleaning procedures while working with cytostatics are divided into: routine cleaning activities and ones after incidents. In the cases of spill it is necessary that the personnel keep to the adequate behavior according to the approved procedure rules and rendering first-aid help. $69 \%$ of the respondents are familiar with the behavioral algorithm in extreme situations, $8 \%$ demonstrate uncertainty and $23 \%$ of the respondents do not know the rules which puts them at high risk when there occur spill incidents (Figure 3).

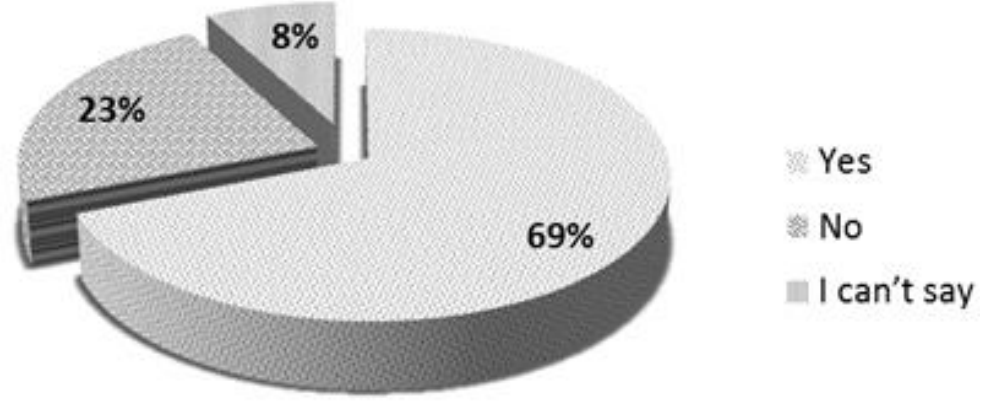

Figure 3. Percentage of the knowledge about the behavioral algorithm when there occurs spill of cytostatics onto the surface. 
Another important factor for safe working of the medical personnel with cytostatics is the proper gathering and dumping of wastes that are considered dangerous. For gathering, dumping and destroying of cytostatic wastes are kept the requirements of the decrees for hazardous loads and the applied in every different country other law norms. All questioned nurses have answered that they know the regulations for gathering and dumping of cytostatic wastes and they have stated that the hazardous wastes and the objects contaminated with them are gathered separately from the other wastes in special containers that are hermetically closed and are designated with special symbols. The results from the conducted research give us grounds to make the following conclusions:

- The majority of the respondents $81 \%$ have gone through training for working with cytostatics on their workplace and only $19 \%$ a specialized course.

- A considerable part of the questioned people would like to participate in trainings and seminars.

- Their motivation to attend courses, at highest rate, is the opportunity to receive up-to-date information and novelties on the topic for safe working with cytostatics.

- In connection to the respondents' personal protection can be noticed serious lapse and negligent attitude towards using preventive means while working with cytostatics.

\section{RECOMMENDATIONS:}

- Proper technical equipment of the specialized sections (ventilation, personal preventive means, closed systems);
PASKALEVA T., et al.

- Monitoring of the preparation, transportation and application of the cytostatic medicines;

- Regular medical examinations;

- Precautions for observation of the exposition of the people working with cytostatics - measurements of the air, observations through tests with smears.

- Regular trainings and increase of the qualification of the medical personnel, working with cytostatics.

\section{CONCLUSION}

The organization and implementation of treatment with cytostatics besides therapeutical is also a highly risky process. The use of up-to-date equipment and highly-technological systems for dissolving of cytostatics, personal preventive means, as well as the approved procedures (transportation, gathering and dumping of wastes) considerably lower the risks for the medical personnel. In our country, unfortunately, it is still not what is defined as the safest, most secure and effective practice for working with cytostatics due to some existing objective reasons. It is for sure that the nowadays reality and the good practices worldwide are the future that is to come.

\section{REFERENCES:}

1. Handbook for prevention and good practices - „Risks for the health and safe working conditions in the healthcare sector", Luxembourg, 2013.

2. http://www.crios.be/cytostatics/genotox $\% 2$ 0lit/Sessink\%20et\%20al.htm

3. http://www.sbaloncology.bg

4. Directive (89/391/EIO) for implementing measurements for encouraging the improvement of safety and health of the employees at their workplace, 1989. 